\title{
Effects of newly developed synbiotic and commercial probiotic products on the haematological indices, serum cytokines, acute phase proteins concentration, and serum immunoglobulins amount in sows and growing pigs - a pilot study
}

\author{
Ewelina Czyżewska-Dors ${ }^{1}$, Krzysztof Kwit $^{1}$, Ewelina Stasiak ${ }^{1}$, \\ Jarosław Rachubik ${ }^{2}$, Katarzyna Śliżewska ${ }^{4}$, Małgorzata Pomorska-Mól ${ }^{1,3}$ \\ ${ }^{1}$ Department of Swine Diseases, ${ }^{2}$ Department of Radiobiology, \\ National Veterinary Research Institute, 24-100 Pulawy, Poland \\ ${ }^{3}$ Department of Preclinical Sciences and Infectious Diseases, Faculty of Veterinary Medicine and Animal Science, \\ Poznań University of Life Sciences, 60-637, Poznań, Poland, \\ ${ }^{4}$ Department of Biotechnology and Food Sciences, Institute of Fermentation Technology and Microbiology, \\ Łódź University of Technology, 90-924 Łódź, Poland \\ mpomorska@piwet.pulawy.pl
}

Received: March 30, $2018 \quad$ Accepted: September 21, 2018

\begin{abstract}
Introduction: The aim of the study was to determine the effects of supplementation of sows' and growing pigs' diets with three newly developed synbiotic and two extant commercial probiotic products on selected immune parameters under field conditions. Material and Methods: The study was performed on 30 sows and 48 piglets of the Danbred breed. Immune parameters such as concentration and proportion of white blood cells and their subpopulations, immunoglobulins amount in serum, and serum concentration of cytokines and acute phase proteins were recorded with the use of a haematology analyser and ELISA kits. Results: No significant differences between treatment groups and controls were found with regard to the immune parameters evaluated except for serum immunoglobulin concentration, which was significantly increased by synbiotic products B and $\mathrm{C}$ and probiotic product D. Conclusion: The results of the study indicate that the synbiotic products $\mathrm{B}$ and $\mathrm{C}$ and probiotic product $\mathrm{D}$ are worthy of further investigation as promising candidates to improve the immune status of healthy sows and their offspring.
\end{abstract}

Keywords: pigs, synbiotics, probiotics, immune parameters.

\section{Introduction}

For several years, sub-therapeutic doses of antibiotics have been used to prevent infectious diseases, improve pig performance and reduce medication costs. However, due to the association of the use of sub-therapeutic doses of antibiotics in feed with the increasing emergence of antibiotic-resistant bacteria, since the 2006 the use of antibiotics as feed additives has been banned in the European Union (20).
In this scenario, the latest research indicates probiotic supplementation in pigs to be a better alternative to infeed antibiotics. Probiotics are a way to both produce animals safely and combat economic losses in pig farming. Probiotics are defined as live microorganisms which confer a health benefit on the host when administered in adequate amounts (7). Prebiotics are non-digestible feed ingredients that selectively stimulate the growth of favourable species of bacteria in the gut. When prebiotics and probiotics are used 
together, they are termed synbiotics and are able to improve the viability of beneficial gut microflora (9). The species currently used in probiotic preparations are bacteria belonging to the genera Lactobacillus, Bifidobacterium, Bacillus, Enterococcus, or Saccharomyces, while the most commonly used prebiotics are galactooligosaccharides (GOS), fructooligosaccharides (FOS), and inulin (16, 34). Many probiotic bacterial strains have been tested for their achievement of reduction of diarrhoea, improvement of pig performance and growth, gut microbial profile modulation, intestinal barrier function, and intestinal morphology $(6,13)$ among other beneficial effects. It has been documented that oral administration of Lactobacillus fermentum improved intestinal health and reduced the number of potential entero-pathogens like Escherichia coli and Clostridia in neonatal piglets (14). Probiotic Enterococcus faecium supplementation reduced the incidence of post-weaning diarrhoea and overall preweaning mortality (28). Another probiotic strain, Bacillus cereus var. toyoi, reduced the occurrence of diarrhoea in piglets challenged with Salmonella Typhimurium (25). Dietary Lactobacillus rhamnosus GG (LGG) supplementation could alleviate diarrhoea in rotavirus (RV)-challenged weaned piglets (18). Moreover, the addition of E. faecium to weaned pigs' diet improved growth and feed conversion, and provision of a combination of E. faecium, Lactobacillus acidophilus, Pediococcus, and Lactobacillus plantarum in their diet increased feed intake, weight gain, and feed conversion (2, 8, 17). Furthermore, dietary supplementation of a Bacillus licheniformis and Bacillus subtilis mixture improved weight gain and reduced mortality of growing-finishing pigs (3). A study conducted in sows also showed that administration of Lactobacillus johnsonii XS4 in diets towards the end of pregnancy and during lactation had positive effects on the performance of sows, increasing litter weight at birth, 20-day litter weight, the number of piglets at weaning, and weaning weight of piglets (31). Besides the aforementioned effects, dietary supplementation with probiotics influenced local intestinal immunity and whole-body systemic immunity. It was reported that some strains of Lactobacillus may recruit various cytokines, and thus they are capable of acting as immunomodulators by enhancing macrophage activity, increasing the local antibody levels, inducing interferon production, and activating killer cells $(13,22)$. For example, dietary L. rhamnosus supplementation increases secretory immunoglobulin A (sIgA) concentrations and attenuates the elevation of serum interleukin-6 (IL-6) induced by enterotoxigenic Escherichia coli (ETEC) K88 in weaned piglets (33). Similarly, E. faecium increases intestinal $\operatorname{IgA}$ secretion both in sows and piglets (23) and could attenuate ETEC K88-induced interleukin-8 (IL-8) secretion in enterocytes (29).
L. fermentum reduced mRNA expression of interleukin-1 $\beta$ (IL-1 $\beta$ ) and reduced numbers of Clostridium sp. in neonatal piglets (15). In addition, a significant benefit from probiotic bacteria with or without prebiotic supplementation has also been observed in various categories of pigs, represented by improved serum immunoglobulin level $(4,31,32)$.

However, studies on the effect of probiotics on the systemic immunity of pigs under field conditions are relatively limited and often contradictory. Therefore, the object of the current experiment was to evaluate under these conditions the effect of supplementation of sow and growing pig diets with three newly developed synbiotic and two off-the-shelf probiotic products on selected immune parameters (haematological indices, serum cytokines, acute phase proteins concentrations, and serum immunoglobulins amount).

\section{Material and Methods}

Management, nutrition and experimental design. The trial was conducted on a privately owned Polish farm, from 2016 to 2017. The owner of the herd gave the permission for the use of the animals in this study.

A farrow-to-finish herd of 100 genetically similar Danbred sows was used. Sows and growing pigs were kept in high-investment indoor facilities. Production was an "all-in, all-out" procedure with a thorough cleaning between batches. Standard farm management included weaning at four weeks of age. The herd was seronegative to pseudorabies virus (PRV), porcine reproductive and respiratory syndrome virus (PRRSV), swine influenza virus (SIV), and Mycoplasma hyopneumoniae (Mhp). No evidence of streptococcosis, pleuropneumonia, Glässers disease, or atrophic rhinitis was recorded based on clinical, serological, and pathological examinations. The immunological study was performed on 30 sows and 48 piglets, comprising both females and castrated males. All sows were of similar body weight $(256.7 \pm 16.4 \mathrm{~kg})$ and in parities 3 to 5. Sows and their offspring were divided into six groups (A, B, C, D, E and K). Piglets from groups A-E $(\mathrm{n}=8$ each) were born from synbiotic/probiotic supplemented sows, while piglets from group $\mathrm{K}(\mathrm{n}=8)$ were born from control sows given no supplements. Sows from all groups were fed a basal diet (Table 1) which for experimental sows was supplemented with commercial probiotic or newly developed synbiotic products, according to the scheme presented in Table 2. Piglets were weaned at 28 days of life and assigned to one of six groups. Weaners from groups $\mathrm{A}$ to $\mathrm{E}$ received synbiotic or probiotic products with a basal diet (Table 1) from two weeks of age until slaughter (24 weeks of age) at a dose of $0.5 \mathrm{~kg}$ per ton of feed. The control group (K) was fed solely a basal diet. For the experimental groups, the basal diet was mixed with 
synbiotic or probiotic products in a mixing device ex tempore. All experimental groups and the control group were housed and managed similarly.

Sampling. Blood from sows was collected at seven days before parturition, at weaning, and seven days post weaning, and from piglets at 7, 28, 35, 73, 105, 135, and 165 days of age. Blood samples were collected via vena cava cranialis venipuncture to vacuum tubes containing EDTA-K3 as an anticoagulant (Medlab, Poland) and to serum separator tubes (Medlab, Poland). Immediately after collection, blood samples were sent to the laboratory in a transport container $\left(4^{\circ} \mathrm{C}\right)$. In the laboratory serum was separated from the blood by centrifugation $(3,000 \mathrm{~g} \times 15 \mathrm{~min}$ at $4^{\circ} \mathrm{C}$ ) and stored at $-20^{\circ} \mathrm{C}$ until analysis.

Table 1. Ingredient composition and chemical analysis of the basal diet ( $\mathrm{g} / \mathrm{kg}$ as-fed basis unless stated otherwise)

\begin{tabular}{|c|c|c|c|c|c|}
\hline Ingredient & Lactating sow & $\begin{array}{l}\text { Prestarter } \\
(2-8 \text { weeks })\end{array}$ & $\begin{array}{l}\text { Starter } \\
(8-12 \text { weeks) }\end{array}$ & $\begin{array}{l}\text { Grower } \\
\text { (12-18 weeks) }\end{array}$ & $\begin{array}{l}\text { Finisher } \\
\text { (18-24 weeks) }\end{array}$ \\
\hline Oats & 100 & - & - & - & 150 \\
\hline Barley & 250 & 220 & 370 & 125 & 200 \\
\hline Triticale & 110 & - & - & 544 & 361 \\
\hline Wheat & 362 & 300 & 400 & 125 & 150 \\
\hline Soybean meal & 90 & 50 & - & 100 & 110 \\
\hline Soybean oil & 10 & 20 & 20 & 15 & 5 \\
\hline Soybean meal HP + fish meal & 40 & - & - & - & - \\
\hline Post-extraction soybean meal, heat-treated & - & 25 & 140 & - & - \\
\hline Soybeans, full-fat, heat-treated & - & 50 & - & - & - \\
\hline Rapeseed meal & - & - & - & 60 & - \\
\hline Whey permeate & - & 50 & - & - & - \\
\hline Monocalcium phosphate & 2 & - & - & - & - \\
\hline LonoFish $^{\mathrm{a}}$ & - & 50 & 25 & - & - \\
\hline Specilac $^{b}$ & - & 40 & - & - & - \\
\hline Lonacid $\mathrm{Max}^{\mathrm{c}}$ & - & 5 & 4 & 1 & - \\
\hline LonoGrain $^{\mathrm{d}}$ & - & 150 & - & - & - \\
\hline Mycofix PLUS ${ }^{e}$ & - & - & 1 & - & - \\
\hline Vitamin-mineral-amino acid premix ${ }^{1}$ & 36 & - & - & - & - \\
\hline Vitamin-mineral-amino acid premix ${ }^{2}$ & - & 40 & - & - & - \\
\hline Vitamin-mineral-amino acid premix ${ }^{3}$ & - & - & 40 & - & - \\
\hline Vitamin-mineral-amino acid premix ${ }^{4}$ & - & - & - & 30 & 25 \\
\hline \multicolumn{6}{|l|}{ Chemical composition } \\
\hline Metabolisable energy (MJ/kg) & 13.1 & 13.8 & 13.8 & 13.6 & 13.5 \\
\hline Crude protein $(\%)$ & 16.5 & 18.8 & 17.9 & 16.8 & 15.6 \\
\hline Lysine (\%) & 0.88 & 1.56 & 1.28 & 1.05 & 0.95 \\
\hline Methionine + Cysteine $(\%)$ & 0.59 & 0.82 & 0.76 & 0.66 & 0.57 \\
\hline Threonine (\%) & 0.58 & 0.87 & 0.79 & 0.67 & 0.56 \\
\hline Tryptophan (\%) & 0.20 & 0.30 & 0.20 & 0.19 & 0.18 \\
\hline Valine (\%) & 0.76 & 0.75 & 0.79 & 0.75 & 0.71 \\
\hline Calcium (\%) & 1.03 & 0.91 & 0.86 & 0.68 & 0.67 \\
\hline Phosphorus (\%) & 0.47 & 0.61 & 0.55 & 0.47 & 0.38 \\
\hline Vitamin A (IU/kg) & 12,500 & 14,000 & 20,500 & 12,000 & 7,700 \\
\hline Vitamin D3 (IU/kg) & 2,000 & 2,000 & 2,000 & 2,000 & 1,540 \\
\hline Vitamin E (mg/kg) & 80 & 84 & 100 & 63 & 100 \\
\hline
\end{tabular}

$\mathrm{a}$ - protein source; $\mathrm{b}$ - protein-lactose rich feed additive; $\mathrm{c}$ - dry mixture of phosphoric acid, formic acid, propionic acid, lactic acid, citric acid, acetic acid, and benzoic acid; $\mathrm{d}$ - micronised wheat, barley, and maize; $\mathrm{e}$ - toxin deactivator

1 - MPU 4\% L.K. T.CH., Cargill Poland; 2 - MPU 4\% PRESTART. T.CH., Cargill Poland; 3 - MPU 4\% START.T.CH., Cargill Poland; 4 - MPU 3/2.5\% GROW/FIN, Cargill Poland 
Table 2. Synbiotic and probiotic composition, dosage, and supplementation scheme (sows and offspring)

\begin{tabular}{|c|c|c|c|c|c|}
\hline Group & Product & Composition & Dose & $\begin{array}{l}\text { Period of } \\
\text { supplementation } \\
\text { (sows) }\end{array}$ & $\begin{array}{l}\text { Period of } \\
\text { supplementation } \\
\text { (growing pigs) }\end{array}$ \\
\hline A & A & $\begin{array}{l}\text { Lactobacillus reuteri ŁOCK } 1092 \\
\text { Lactobacillus plantarum ŁOCK } 0860 \\
\text { Lactobacillus pentosus ŁOCK } 1094 \\
\text { Saccharomyces cerevisiae ŁOCK } 0118 \\
\text { Inulin }\end{array}$ & & & \\
\hline B & B & $\begin{array}{l}\text { Lactobacillus reuteri ŁOCK } 1092 \\
\text { Lactobacillus plantarum ŁOCK } 0860 \\
\text { Lactobacillus pentosus ŁOCK } 1094 \\
\text { Saccharomyces cerevisiae ŁOCK } 0118 \\
\text { Lactobacillus rhamnosus ŁOCK } 1087 \\
\text { Inulin }\end{array}$ & & & \\
\hline $\mathrm{C}$ & $\mathrm{C}$ & $\begin{array}{l}\text { Lactobacillus reuteri ŁOCK } 1092 \\
\text { Lactobacillus plantarum ŁOCK } 0860 \\
\text { Lactobacillus pentosus ŁOCK } 1094 \\
\text { Saccharomyces cerevisiae ŁOCK } 0118 \\
\text { Lactobacillus rhamnosus ŁOCK } 1087 \\
\text { Lactobacillus paracasei ŁOCK } 1091 \\
\text { Inulin }\end{array}$ & $\begin{array}{l}0.5 \mathrm{~kg} / \mathrm{ton} \\
\text { of basal diet }\end{array}$ & $\begin{array}{l}10 \text { days before } \\
\text { farrowing until } \\
\text { weaning }\end{array}$ & $\begin{array}{l}\text { from } 2 \text { weeks of } \\
\text { age until slaughter }\end{array}$ \\
\hline $\mathrm{D}$ & $\begin{array}{l}\text { Cylactin } \\
\text { LBC }\end{array}$ & $\begin{array}{l}\text { Bacillus subtilis DSM } 5750 \\
\text { Bacillus licheniformis DSM } 5749 \\
\text { calcium carbonate } \\
\text { kieselguhr as anticaking agent } \\
\text { Enterococcus faecium NCIMB } 10415 \\
\text { saccharose as carrier } \\
\text { cellulose derivative as encapsulating agent }\end{array}$ & & & \\
\hline K & NA & NA & NA & NA & NA \\
\hline
\end{tabular}

Haematological examination. Whole blood samples were analysed for different leukocyte proportions and concentrations on an Abacus Junior Vet 5 haematology analyser (Diatron, Hungary) immediately after delivery to the laboratory. The proportions of lymphocytes (LYM) and granulocytes (GRA) were calculated as a percentage of the white blood cell (WBC) concentration.

Measurement of serum immunoglobulins concentration. Total serum concentrations of immunoglobulin A (IgA), immunoglobulin M (IgM), and immunoglobulin $\mathrm{G}$ ( $\mathrm{IgG}$ ) were determined with a commercial ELISA kit (ELISA Quantitation Kit, Bethyl Laboratories Inc, USA), according to the manufacturer's recommendations. The absorbance was recorded at $450 \mathrm{~nm}$, using an ELISA plate reader (Multiskan RC, Labsystems, Finland), and the results obtained (in $\mathrm{ng} / \mathrm{mL}$ ) were multiplied by the appropriate dilution factor and expressed as $\mathrm{mg} / \mathrm{mL}$. In each experiment, serial dilutions of standard samples were tested in order to obtain a calibration curve, which was then computer adjusted (with the use of the FindGraph software programme (UniPhiz, Canada)). From this calibration curve, the values of unknown Ig concentration samples were calculated.

Cytokines and acute phase proteins systemic concentration. The serum concentrations of IL-6, IL-8, interleukin-4 (IL-4), and interleukin-10 (IL-10) were analysed with the commercial Porcine IL-6 and Porcine IL-8 cytokine ELISA kits (RayBiotech Norcross, 
USA), and Swine IL-4 and Swine IL-10 ELISA kit (Life Technologies, USA). All tests were conducted, according to the manufacturers' recommendations. The quantity of cytokines was calculated based on a standard curve for each cytokine with the use of FindGraph software. Concentrations of C-reactive protein (CRP), haptoglobin (Hp), and pig major acutephase protein (Pig-MAP) were determined by commercial ELISA kits, according to the manufacturers' recommendations. The selected kits were the Pig C-Reactive Protein ELISA and Pig Haptoglobin ELISA (Life Diagnostics, Inc., USA) and the PigMAP ELISA (Acuvet Biotech S.L., Spain).

Statistical analysis. Data from all groups were subjected to the Shapiro-Wilk W test of normality and Levene's test of equal variances. In the case of a lack of normality or different variances, a nonparametric Kruskal-Wallis test with post hoc multiple comparisons for comparison of all pairs was used. In the case of normal distribution and equal variances, one-way ANOVA with Tukey's HSD post-test was used. These tests were used for analysis of differences between groups, and all implicated calculations were performed with the Statistica 8.0 (Statsoft, Poland) computer programme.

\section{Results}

Haematological examination. The number of WBC, LYM, and GRA remained stable throughout the study in sows and their piglets from all experimental groups $(\mathrm{P}>0.05)$. Detailed results for the concentrations of WBC, LYM, and GRA, and proportion of LYM and GRA are shown in Figs 1 and 2. The values of all indices were within the reference ranges.
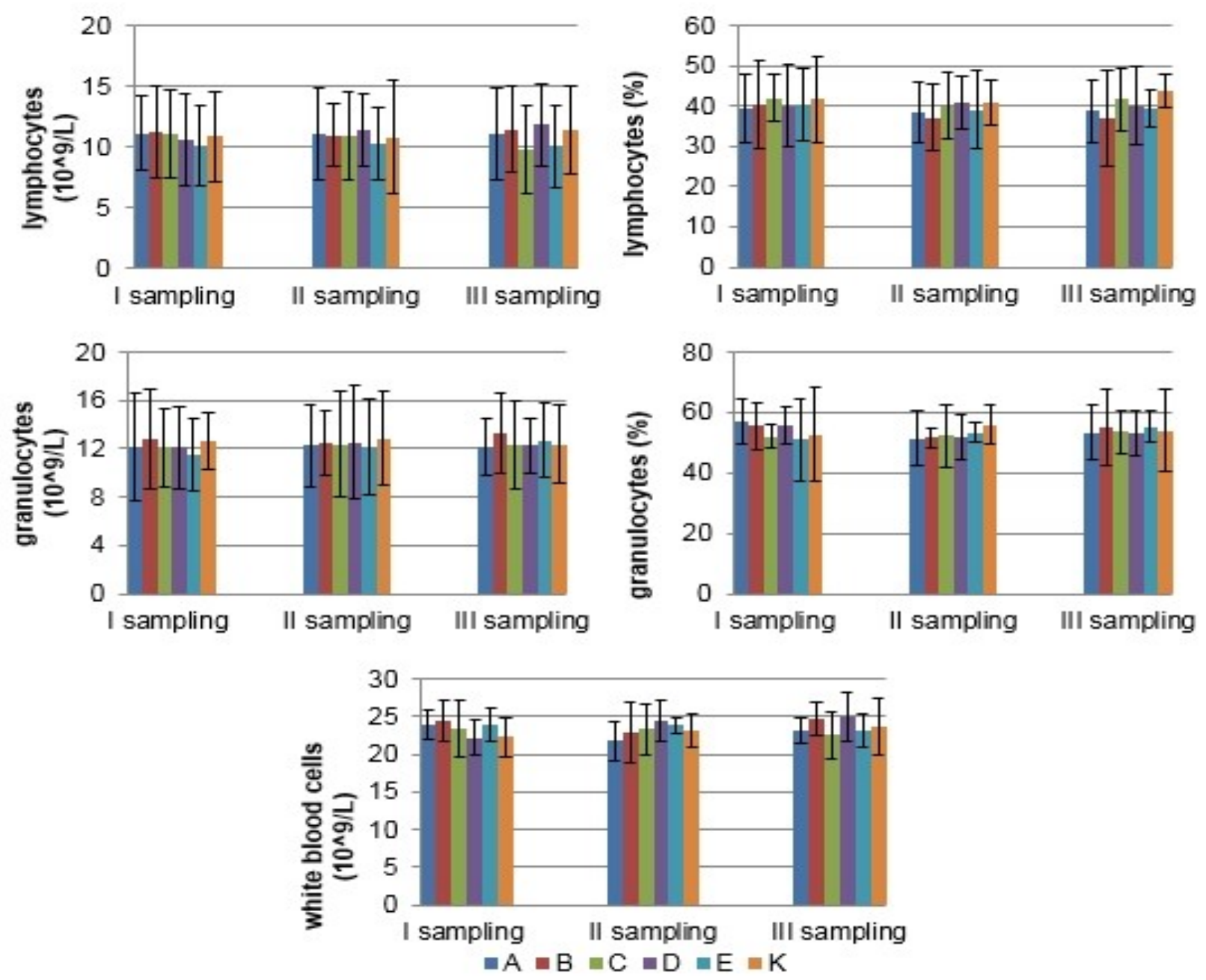

Fig. 1. The mean $( \pm \mathrm{SD})$ concentration of WBC, LYM, and GRA, and proportion of LYM and GRA in blood of sows in different experimental groups 

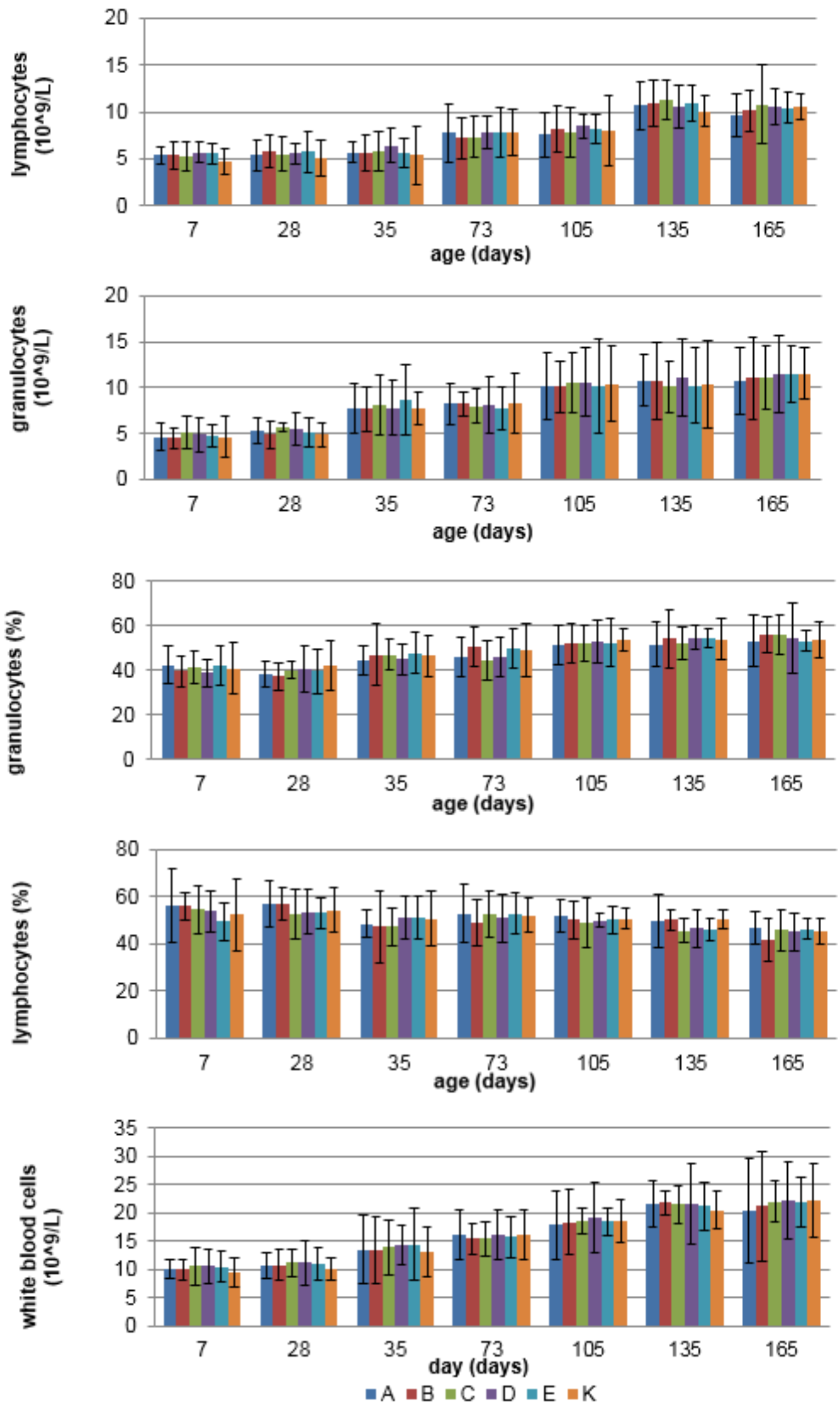

Fig. 2. The mean $( \pm \mathrm{SD})$ concentration of WBC, LYM, and GRA, and proportion of LYM and GRA in blood of growing pigs in different experimental groups 
Measurement of serum immunoglobulin concentration. The effects of the tested synbiotic and probiotic products on serum IgG, IgM, and IgA concentrations of sows and growing pigs are presented in Figs. 3 and 4. In sows supplemented with synbiotic product $\mathrm{C}$, significantly higher serum concentrations of $\operatorname{IgM}$ and $\operatorname{IgA}$ were observed in the $2^{\text {nd }}$ and $3^{\text {rd }}$ samplings, and $\operatorname{IgG}$ in the $3^{\text {rd }}$ sampling only $(\mathrm{P}<0.05)$. Also synbiotic product $\mathrm{B}$ and probiotic product $\mathrm{D}$ significantly affected immunoglobulin concentration for $\operatorname{IgM}$ in the $2^{\text {nd }}$ and $3^{\text {rd }}$ samplings, and $\operatorname{IgA}$ in the $3^{\text {rd }}$ sampling, respectively $(\mathrm{P}<0.05)$. In growing pigs, dietary supplementation with product $\mathrm{C}$ significantly increased serum $\operatorname{IgG}$ concentration over that of the control group on day 165 and $\operatorname{IgM}$ concentration on days 135 and 165 of the study. In addition, in growing pigs treated with probiotic product $\mathrm{D}$, a statistically significant increase in IgM concentration was observed on day 165 as compared to the control $(\mathrm{P}<0.05)$.

Measurement of cytokine and acute phase protein concentration in serum. The serum concentrations of IL-6 and IL-8 were not significantly different from the control group in the synbiotics and probiotics supplemented groups in both sows and growing pigs at any collection period $(\mathrm{P}>0.05)$ (Figs 5 and 6). Concentrations of IL-4 and IL-10 were under the limit of detection (data not shown). Similarly, serum concentrations of CRP, Hp, and Pig-MAP were not significantly affected by the synbiotics and probiotics treatment, either in sows or in the growing pigs (Figs 7 and 8).
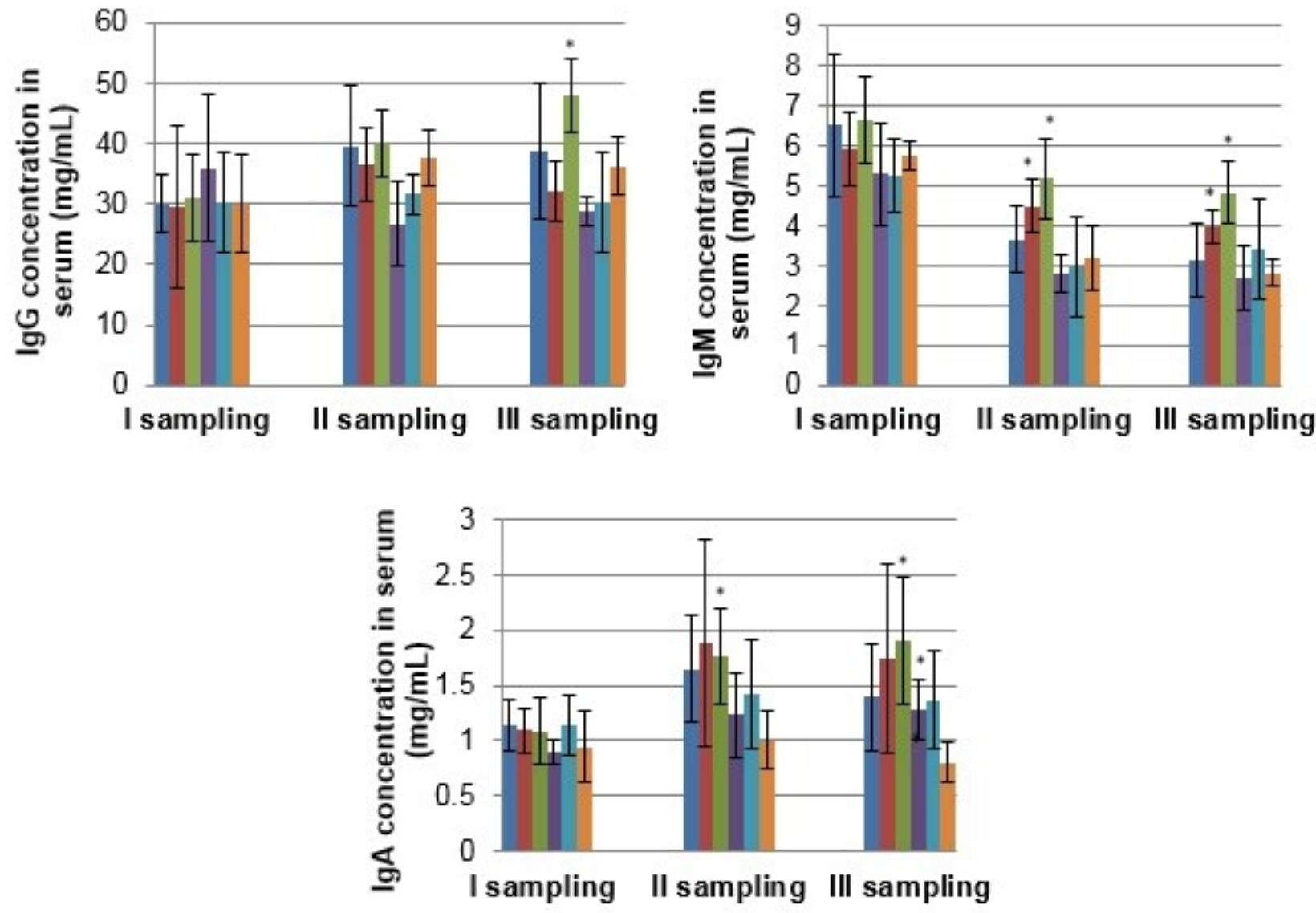

$\because \mathrm{A}=\mathrm{B} \backsim \mathrm{C} \square \mathrm{D} \square \mathrm{E}=\mathrm{K}$

Fig. 3. The mean $( \pm \mathrm{SD})$ serum $\mathrm{IgG}$, IgM and IgA concentration of sows in different experimental groups;

* - statistical difference compared to control group 

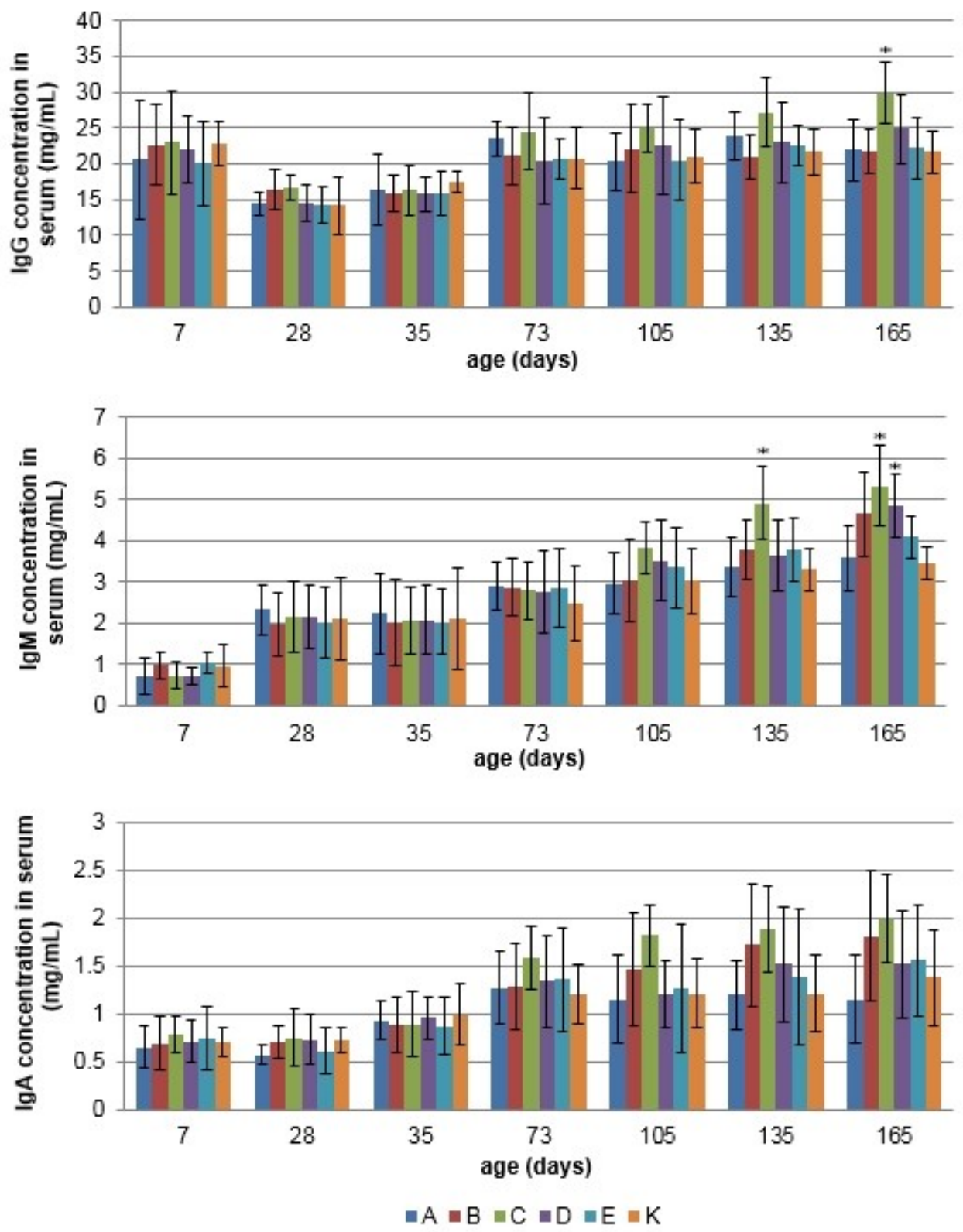

Fig. 4. The mean $( \pm \mathrm{SD})$ serum $\operatorname{IgG}, \operatorname{IgM}$, and $\operatorname{IgA}$ concentration of growing pigs in different experimental groups; * - statistical difference compared to control group
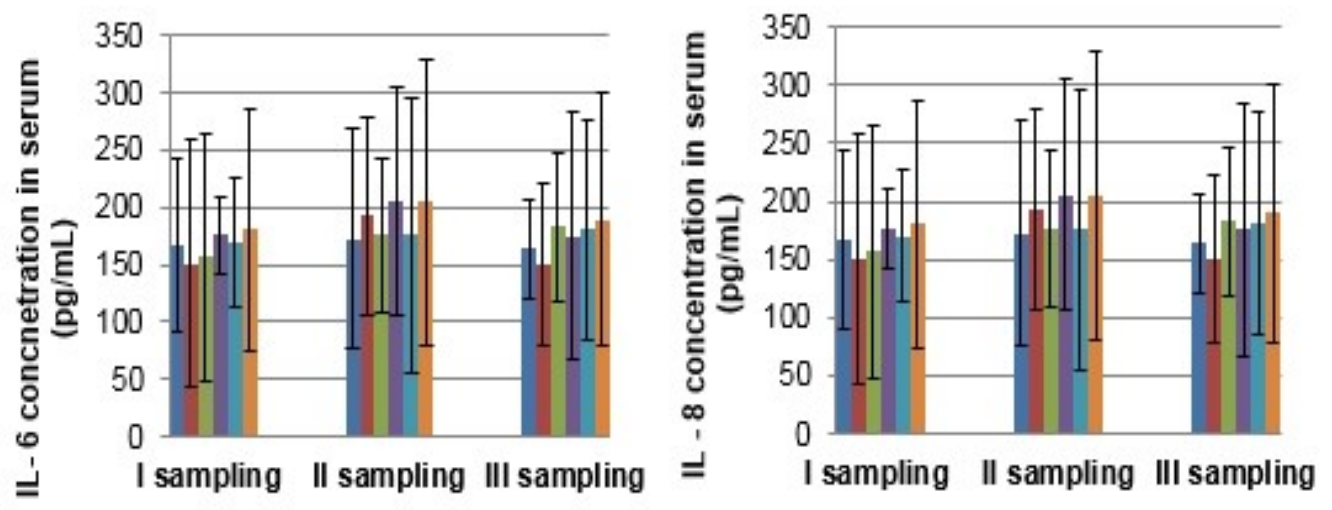

$\because \mathrm{A}\|\mathrm{B}\| \mathrm{C}\|\mathrm{D}\| \mathrm{E} \| \mathrm{K}$

Fig. 5. The mean $( \pm \mathrm{SD})$ interleukin (IL-6 and IL-8) concentration in serum of sows in different experimental groups 

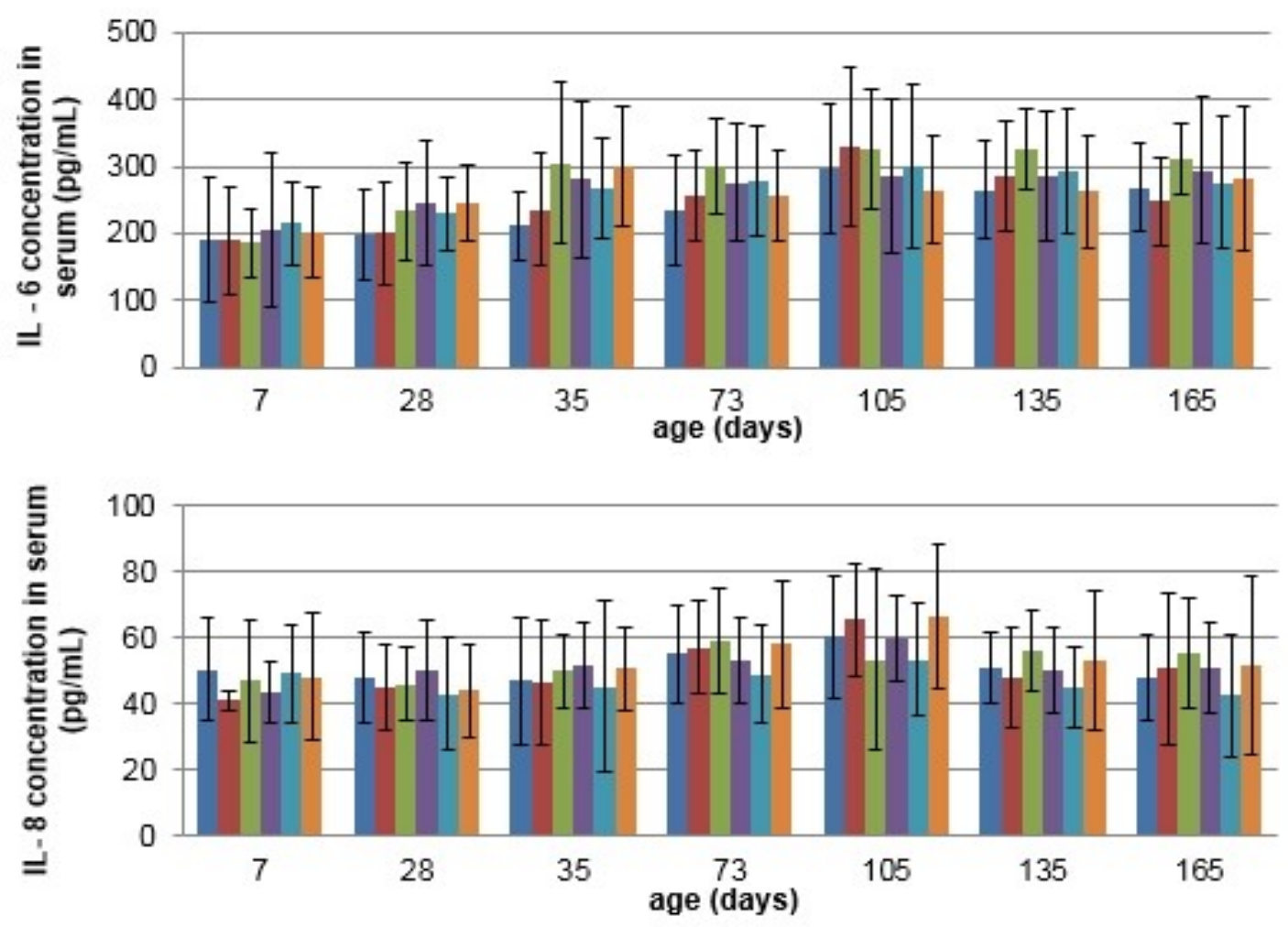

$\because \mathrm{A} \approx \mathrm{B} \approx \mathrm{C} \backsim \mathrm{D} \approx \mathrm{E} \approx \mathrm{K}$

Fig. 6. The mean $( \pm \mathrm{SD})$ IL-6 and IL-8 concentration in serum of growing pigs in different experimental groups
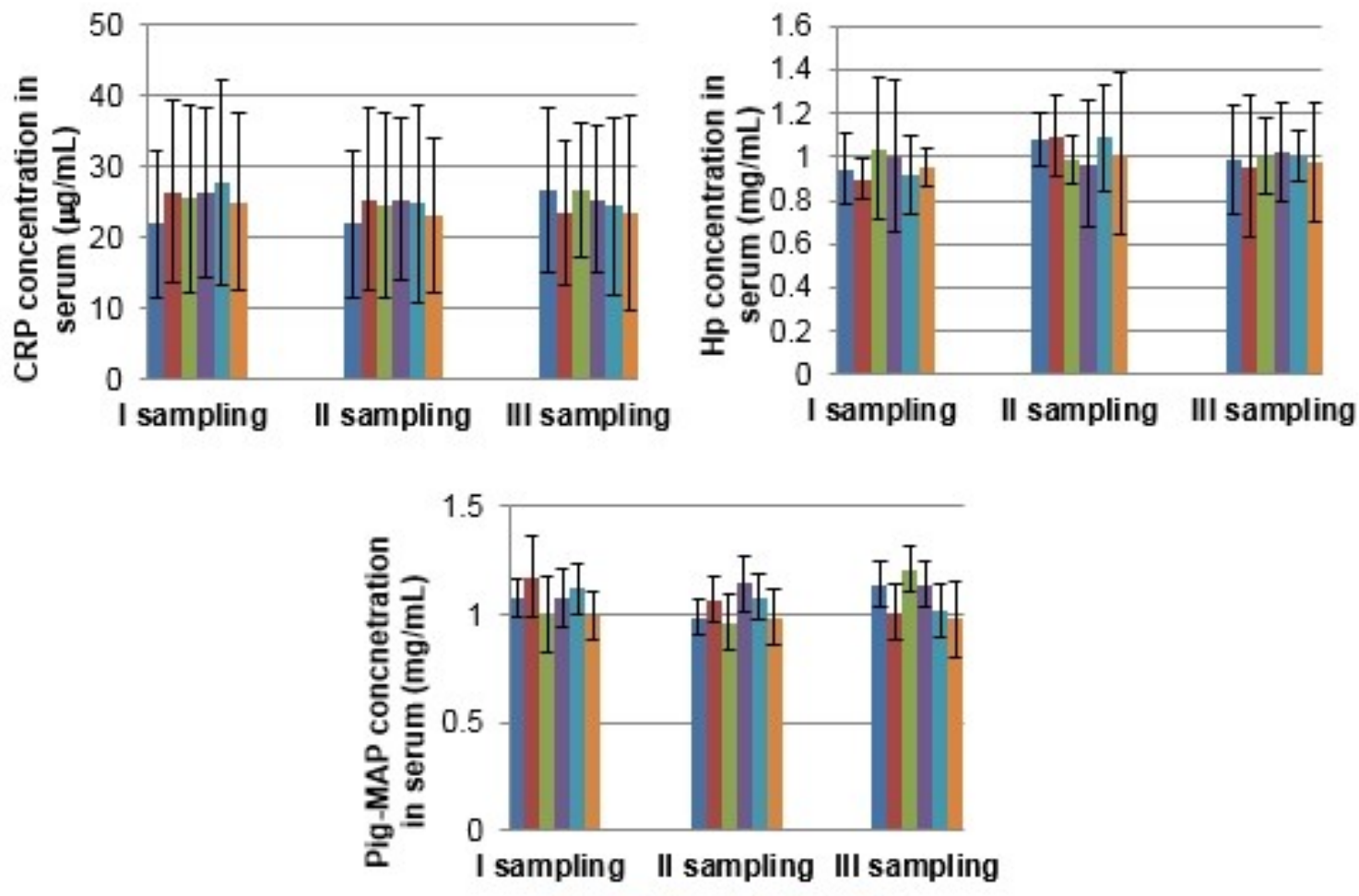

$\because \mathrm{A}\|\mathrm{B} \equiv \mathrm{C}\| \mathrm{D} \| \mathrm{E} \equiv \mathrm{K}$

Fig. 7. The mean $( \pm \mathrm{SD})$ acute phase proteins $(\mathrm{CRP}, \mathrm{Hp}$, and Pig-MAP) concentration in serum of sows in different experimental groups 

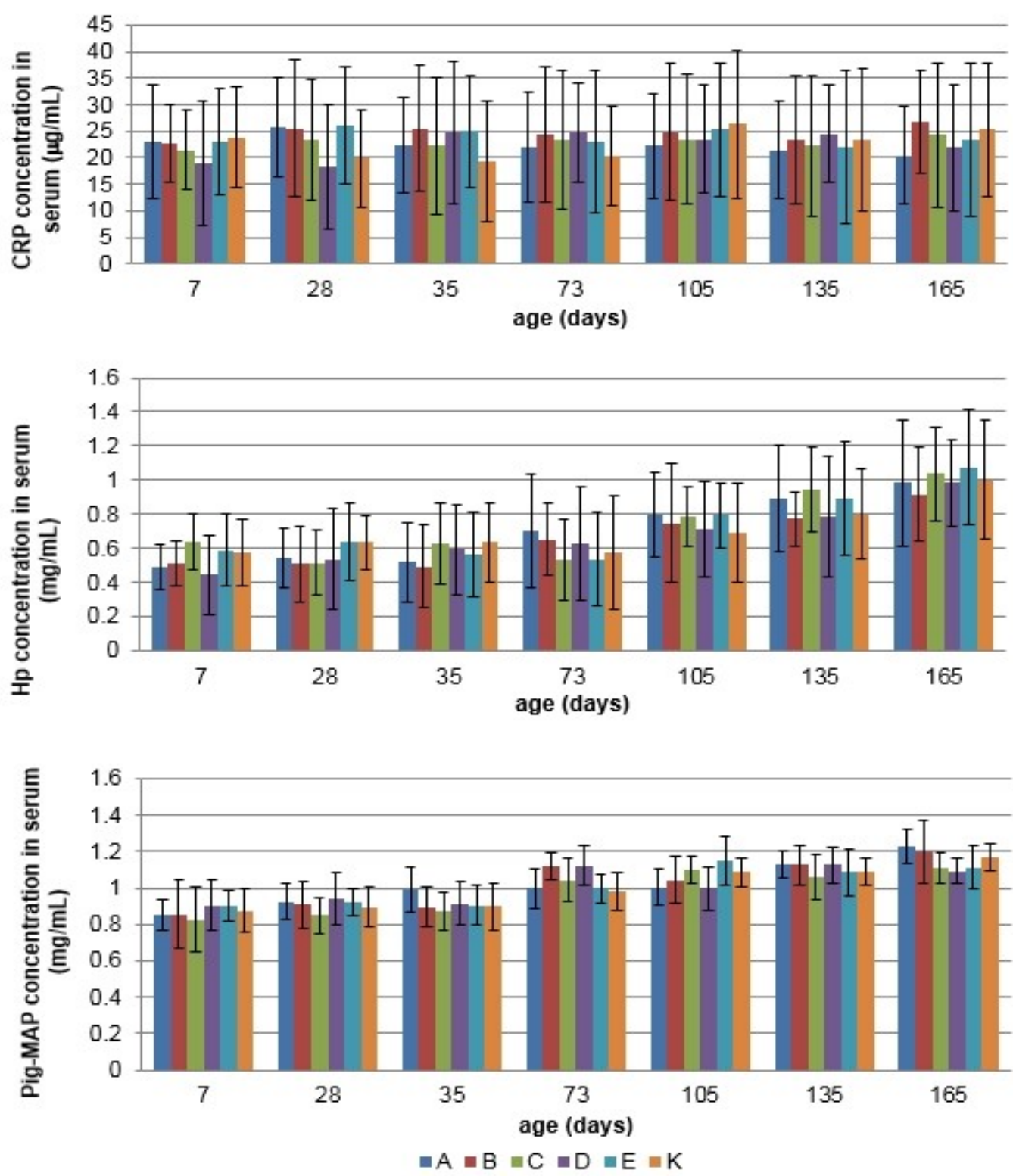

Fig. 8. The mean $( \pm \mathrm{SD})$ acute phase proteins (CRP, Hp, and Pig-MAP) concentration in serum of growing pigs in different experimental groups

\section{Discussion}

The results of the present study show that the addition of newly developed synbiotic and extant commercial probiotic products to the diets of healthy sows and their piglets did not affect the WBC count, LYM or GRA concentrations and their proportions. Similar trends were reported by Shim (26) who found that haematological traits were unaffected by multistrain probiotic (combination of Bifidobacterium longum, L. acidophilus, B. subtilis, Saccharomyces cerevisiae, and Aspergillus oryzae), prebiotic (FOS), and synbiotic (multi-strain probiotic + FOS) treatment in weaned pigs. The results of another study also did not record statistical difference between the WBC count of pigs fed diets supplemented with a two-strain probiotic containing $B$. subtilis and Bacillus licheniformis, a prebiotic containing an extract of yeast cell wall ( $S$. cerevisiae), or synbiotics (a mixture of both feed additives) and the WBC of pigs in a control group (27). Dietary supplementation with probiotic (multi-strain probiotic containing seven bacterial strains and two yeast strains), prebiotic (polysaccharides of $S$. cerevisiae cell wall), or combination of these as additives to milk did not affect significantly WBC, neutrophil, or monocyte counts in newborn female calves (21). In contrast, stimulation of the immune system by supplementation with a mixture of B. subtilis, E. faecium, and $S$. cerevisiae was observed in WBC increases in layer chicks and broilers, respectively $(11,19)$.

In terms of serum cytokine concentration, the present study showed that administration of neither synbiotic nor probiotic products affected concentration of these proteins in serum. Similarly, in neonatal gnotobiotic pigs serum cytokine concentration was not affected by dietary probiotic supplementation combining the two strains of L. acidophilus and 
Lactobacillus reuteri (1). However, in this study, significantly higher concentrations of interferon- $\alpha$ (IFN- $\alpha$ ), interferon- $\gamma$ (IFN- $\gamma$ ), interleukin-12 (IL-12), and IL-10 were observed in pigs supplemented with probiotic bacteria and infected with human rotavirus (HRV) and pigs not supplemented and infected with HRV compared to uninfected, supplemented, and control pigs. These findings indicate that the intestinal immune system is immunotolerant to probiotic bacteria supplementation alone. An immunomodulatory effect of probiotic bacterial strain LGG on systemic proinflammatory cytokine response was observed in weaned pigs challenged with E. coli. Administration of LGG before $E$. coli infection attenuated the elevation of serum IL-6 induced by E. coli (33). Interesting results were observed by Wang et al. (30) who evaluated the systemic immune response represented by interleukin-2 (IL-2), IL-6, TNF- $\alpha$, and IFN- $\gamma$ of weaned pigs to the administration of $L$. fermentum $\mathrm{I} 5007$ with or without an $E$. coli challenge. The results showed that L. fermentum $\mathrm{I} 5007$ supplementation or E. coli challenge had no effect on these cytokines in the serum. Surprisingly, Laskowska et al. (12) observed a statistically significant increase in serum proinflammatory cytokines, i.e. IL-2, IL-6, TNF- $\alpha$, and IFN- $\gamma$, anti-inflammatory cytokines, i.e. IL-4 and IL-10, and the immunoregulatory cytokine transforming growth factor- $\beta$ (TGF- $\beta$ ) in sows supplemented during pregnancy with the EM Bokashi multi-microbial probiotic without any pathogen challenge. In addition, in the aforementioned study, changes in cytokine profile were observed in colostrum, milk, and in the culture of stimulated colostrum polymorphonuclear (PMN) cells. Another study conducted on weaned pigs also documented that inclusion of probiotic bacteria Lactobacillus brevis without any pathogen challenge increased serum IFN- $\gamma$ concentration (15).

Regarding the acute-phase protein values in serum, in the present study, the proteins were not significantly affected by either synbiotic or probiotic products, which might be attributed to the proinflammatory cytokine homeostasis. The same trend was observed by Wang et al. (31) in lactating sows supplemented with the probiotic bacteria Lactobacillus johnsonii XS4, and by Guerra-Ordaz et al. (10) in weaning piglets treated with a combination of Lactobacillus plantarum and lactulose. It might indicate that dietary supplementation with synbiotics and/or probiotics helps animals to maintain good condition and health on the farm.

In this study, the newly developed synbiotic products $\mathrm{B}$ and $\mathrm{C}$ and commercial probiotic product $\mathrm{D}$ enhanced immune activity with a significant increase in serum immunoglobulin concentration in sows and growing pigs, while synbiotic product $\mathrm{A}$ and probiotic product $\mathrm{E}$ did not affect the systemic humoral immune response. A beneficial effect of probiotic treatment was observed by Wang et al. (31) who demonstrated that supplementation of the sow diet with L. johnsonii XS4 during late gestation and lactation led to a significant increase in serum IgG levels. In another study, supplementation with the multi-microbial probiotic EM Bokashi in sows also increased IgG and IgA levels in serum, colostrum, and milk (12). Also in growing pigs, dietary supplementation with $L$. plantarum, B. subtilis, or a mixture of $L$. plantarum and $B$. subtilis enhanced humoral immune response with increased serum concentration of $\operatorname{IgM}$ and $\operatorname{IgA}$ (5). However, for Dong and coworkers, serum IgG amount was not affected by dietary treatments (5). Also inclusion of E. facecium or $B$. cereus var. toyoi in sow diets did not significantly affect IgG concentration in serum $(23,24)$. Similarly, in calves, supplementation with multi-strain probiotic mixed with prebiotic and by itself did not affect $\operatorname{IgG}$ level in serum (21).

The immune parameter discrepancies observed between the present study and other findings may be related to differences in the probiotic strain(s) used, experimental setting, basal diet formulation, age of animals, initial gut microflora composition, amount of synbiotic/probiotic used, time and frequency of synbiotic/probiotic administration, and time of sampling. Whether a probiotic was used alone or in combination with a prebiotic is also a possible root of discordant findings.

In conclusion, the results of our study documented that supplementation of sow and growing pig diets either with newly developed synbiotic products B and $\mathrm{C}$, or probiotic product $\mathrm{D}$ enhanced immune activity by significantly increasing serum immunoglobulins concentration. This finding suggests that these feed additives are worthy of further investigation as good candidates to improve the immune status of pigs in various life stages.

Conflict of Interests Statements: The authors declare that there is no conflict of interests regarding the publication of this article.

Financial Disclosure Statement: This work was supported by the National Centre for Research and Development as part of the project PBS3/A8/32/2015.

Animal Rights Statement: The experiment was approved by the II Local Ethics Committee at the University of Life Sciences in Lublin (4/2015).

\section{References}

1. Azevedo M.S., Zhang W., Wen K., Gonzalez A.M., Saif L.J., Yousef A.E., Yuan L.: Lactobacillus acidophilus and Lactobacillus reuteri modulate cytokine responses in gnotobiotic pigs infected with human rotavirus. Benef Microbes 2012, 3, 33-42.

2. Chen Y.J., Min B.J., Cho J.H., Kwon K.S., Kim I.H., Kim S.J.: Effects of dietary Enterococcus faecium SF68 on growth performance, nutrient digestibility, blood characteristics, and faecal noxious gas content in finishing pigs. Asian-Aust J Anim Sci 2006, 19, 406-411. 
3. Davis M.E., Parrott T., Brown D.C., de Rodas B.Z., Johnson Z.B., Maxwell C.V., Rehberger T.: Effect of a Bacillusbased direct-fed microbial feed supplement on growth performance and pen cleaning characteristics of growingfinishing pigs. J Anim Sci 2008, 86, 1459-1467.

4. Dlamini Z.C., Langa R.L.S., Aiyegoro O.A., Okoh A.I.: Effects of probiotics on growth performance, blood parameters, and antibody stimulation in piglets. S Afr J Anim Sci 2017, 47, 766-775.

5. Dong N., Zhang M., Zhou M., Tu Y., Deng K., Diao Q.: Effects of dietary probiotics on growth performance, faecal microbiota and serum profiles in weaned piglet. J Basic Microbiol 2013, 49, 220-226.

6. Dowarah R., Verma A.K., Agarwal N.: The use of Lactobacillus as an alternative of antibiotics growth promoters: a review. Anim Nutri 2017, 3, 1-6.

7. FAO/WHO.: Probiotics in food health and nutritional properties. FAO Food and Nutrition Paper, Rome, Italy (2002), p. 85.

8. Giang H.H., Viet T.Q., Ogle B., Lindberg J.E.: Growth performance, digestibility, gut environment and health status in weaned piglets fed a diet supplemented with potentially probiotic complexes of lactic acid bacteria. Livest Sci 2010, 129, 95-103.

9. Gibson G.R., Roberfroid M.B.: Dietary modulation of the human colonic microbiota: introducing the concept of prebiotics. J Nutr 1995, 125, 1401-1412.

10. Guerra-Ordaz A.A., Molist F., Hermes R.G., Gomez de Segura A., La Ragione R.M., Woodward M.J., Tchotrzewska M.A., Collins J.W., Perez J.F., Martin-Orue S.M.: Effect of inclusion of lactulose Lactobacillus plantarum on the intestinal environment and performance of piglets at weaning. Anim Feed Sci Tech 2013, 185, 160-168.

11. Hatab M.H, Elsayed M.A., Ibrahim N.S.: Effect of some biological supplementation on productive performance, physiological and immunological response of layer chicks. J Radiat Res Appl Sci 2016, 9, 185-192.

12. Laskowska E., Jarosz Ł., Gradzki Z.: Effect of multi-microbial probiotic formulation Bokashi on pro- and anti-inflammatory cytokines profile in the serum, colostrum and milk of sows, and in a culture of polymorphonuclear cells isolated from colostrum. Probiotics Antimicrob Proteins 2018.

13. Liao F., Nyachoti M.: Using probiotics to improve swine gut health and nutrient utilization. Anim Nutr 2017, 3, 331-343.

14. Liu H., Zhang J., Zhang S., Yang F., Thacker P.A., Zhang G., Ma X.: Oral administration of Lactobacillus fermentum I5007 favors intestinal development and alters the intestinal microbiota in formula-fed piglets. J Agric Food Chem 2014, 62, 860-866.

15. Liu H., Ji H.F., Zhang D.Y., Wang S.X., Wang J., Shan D.C., Wang Y.M.: Effects of Lactobacillus brevis preparation on growth performance, fecal microflora and serum profile in weaned pigs. Livestock Sci 2015, 178, 251-254.

16. Macfarlane G.T., Steed H., Macfarlane S.: Bacterial metabolism and health-related effects of galactooligosaccharides and other prebiotics. J Appl Microbiol 2008, 104, 305-344.

17. Malloa J.J., Rioperezb J., Honrubiaa P.: The addition of Enterococcus faecium to diet improves piglet's intestinal microbiota and performance. Livest Sci 2010, 26, 243-256.

18. Mao X., Gu C., Hu H., Tang J., Chen D., Yu B., He J., Yu J., Luo J., Tian G.: Dietary Lactobacillus rhamnosus GG supplementation improves the mucosal barrier function in the intestine of weaned piglets challenged by porcine Rotavirus. PLoS One 2016, 11, e0146312

19. Paryad A., Mahmoudi M.: Effect of different levels of supplemental yeast (Saccharomyces cerevisiae) on performance, blood constituents and carcass characteristics of broiler chicks. Afr J Agric Res 2008, 3, 835-842.
20. Regulation $1831 / 2003 / \mathrm{EC}$ on additives for use in animal nutrition, replacing Directive $70 / 524 / \mathrm{EEC}$ on additives in feeding-stuffs. OJ L 268, 18.10.2003, pp. 29-43.

21. Roodposhti P.M., Dabiri N.: Effects of probiotic and prebiotic on average daily gain, fecal shedding of Escherichia coli, and immune system status in newborn female calves. Asian-Aust J Anim Sci 2011, 25, 1255-1261.

22. Rosellia M., Pieper R., Rogel-Gaillard C., de Vries H., Bailey M., Smidt H., Lauridsen C.: Immunomodulating effects of probiotics for microbiota modulation, gut health and disease resistance in pigs. Anim Feed Sci Tech 2017, 233, 104-119.

23. Scharek L., Guth J., Filter M., Schmidt M.F.: Impact of the probiotic bacteria Enterococcus faecium NCIMB 10415 (SF68) and Bacillus cereus var. toyoi NCIMB 40112 on the development of serum $\operatorname{IgG}$ and faecal $\operatorname{IgA}$ of sows and their piglets. Arch Anim Nutr 2007, 61, 223-234.

24. Scharek L., Guth J., Reiter K., Weyrauch K.D., Taras D., Schwerk P., Schierack P., Schmidt M.F.G., Wieler L.H., Tedin K.: Influence of a probiotic Enterococcus faecium strain on development of the immune system of sows and piglets. Vet Immunol Immunopathol 2005, 105, 151-161.

25. Scharek-Tedin L., Pieper R., Vahjen W., Tedin K., Neumann K., Zentek J.: Bacillus cereus var. toyoi modulates the immune reaction and reduces the occurrence of diarrhea in piglets challenged with Salmonella typhimurium DT104. J Anim Sci 2013, 91, 5696-5704.

26. Shim S.B.: Effects of prebiotics, probiotics and synbiotics in the diet of young pigs. Ph.D. Thesis. Animal Nutrition Group, Wageningen Institute of Animal Sciences, Wageningen University and Research Centre, 2005, Wageningen, Netherlands.

27. Szakacs A-R., Matei S., Stefanut L., Moni Z., Macri A.: Effects of pre and probiotic on growth performance and haematological parameters in pigs. Bull UASVM Vet Med 2009, 73, 265-300.

28. Taras D., Vahjen W., Macha M., Simon O.: Performance, diarrhea incidence, and occurrence of Escherichia coli virulence genes during long-term administration of a probiotic Enterococcus faecium strain to sows and piglets. J Anim Sci 2006, 84, 607-617.

29. Tian Z., Liu X., Dai R., Xiao Y., Wang X., Bi D., Shi D.: Enterococcus faecium HDRsEfl protects the intestinal epithelium and attenuates ETEC-induced IL-8 secretion in enterocytes. Mediat Inflamm 2016, 5, 1-10.

30. Wang A., Yu H., Gao X., Li X., Qiao S.: Influence of Lactobacillus fermentum $\mathrm{I} 5007$ on the intestinal and systemic immune responses of healthy and $E$. coli challenged piglets. Antonie Van Leeuwenhoek 2009, 96, 89-98.

31. Wang J., Ji H.F., Hou C.L., Wang S.X., Zhang D.Y., Liu H., Shan D.C., Wang Y.M.: Effect of Lactobacillus johnsonii XS4 supplementation on reproductive performance, environment, and blood biochemical and immunological index in lactating sows. Livestock Sci 2014, 164, 96-101

32. Wang W., Chen J., Zhou H., Wang L., Ding S., Wang Y., Song D., Li A.: Effects of microencapsulated Lactobacillus plantarum and fructooligosaccharide on growth performance, blood immune parameters, and intestinal morphology in weaned piglets. Food Agr Immunol 2017, 29, 84-94.

33. Zhang L., Xu Y.X., Liu H.Y., Lai T., Ma J.L., Wanga J.F., Zhu Y.H.: Evaluation of Lactobacillus rhamnosus GG using an Escherichia coli K88 model of piglet diarrhoea: Effects on diarrhea incidence, faecal microflora and immune responses. Vet Microbiol 2010, 141, 142-148.

34. Zimmermann B., Bauer E., Mosenthin R.: Pro- and prebiotics in pig nutrition - potential modulators of gut health? Anim Feed Sci $2001,10,47-56$ 